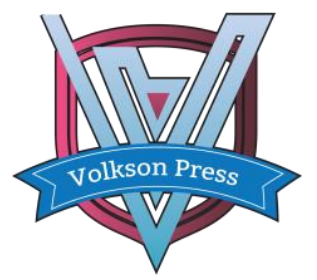

Contents List available at VOLKSON PRESS

Clean Water,Air\&Soil(CleanWAS)

DOI : http://doi.org/10.26480/cleanwas.01.2017.30.32

\title{
Some Suggestions on Solving Storm Water Logging in Cities
}

Xinwen Wang

Department of Civil Engineering, Luoyang Institute of Science and Technology, Luoyang, China wangxw2015@163.com

This is an open access article distributed under the Creative Commons Attribution License, which permits unrestricted use, distribution, and reproduction in any medium, provided the original work is properly cited

\section{ARTICLE DETAILS}

\section{Article History:}

Received 02 october 2017

Accepted 06 october 2017

Available online 11 october 2017

Keywords:

City, Rainwater Pipe Network,

Storm Runoff, Water Logging.

\section{ABSTRACT}

In order to avoid storm water logging of the cities in china, reasonable arrangement and accurate design calculation of the new and rebuilt and expanded rainwater pipe networks are carried out, city construction engineering take into account the reduction of storm runoff, and rechecking city construction engineering and rainwater pipe network design using storm water logging forecasting early-warning system, it can radically avoid storm water logging in city; Through proper modification of rainwater pipe network at water logging area, straightening out the connection between rainwater pipe network and urban river, canal and lake, Timely desilting, checking and repairing leakage of rainwater pipe, and examining the pipes with forecasting early-warning system, the water logging hazard in cities can be eliminated.

\section{Introduction}

In recent years, extreme weather had occurred in every province of our country due to various reasons, especially that rainstorm events occurred more. Rainstorm caused so much serious consequences around the area that the video and photo of "to see the sea" to a urban keep appearing online[1]. Storm water logging brings inconvenience to city dwellers, even endanger the safety of their lives and property. Around on May 10th, 2016, a storm appeared and caused severe areas of water logging in Quanzhou,China, which are shown in Fig1 [2].Therefore, it is urgent to solve the problem of rainstorm water logging in Chinese cities.

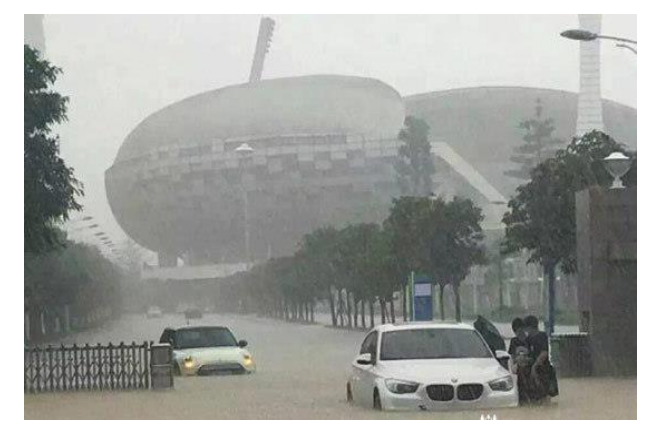

(1)

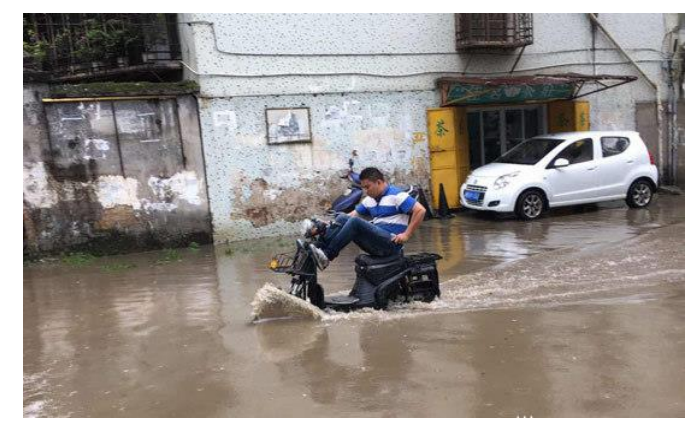

(2)
Fig1. Photo of storm water logging in Quanzhou on May 10th, 2016

2. Cause analysis for storm water logging in cities

In order to find the solution to the storm water logging in the cities, first of all, the causes of storm water logging are investigated and analyzed. It is found that the following factors are the main cause of storm water logging in the cities:

\subsection{Low-lying topography}

The formation of urban storm water has a lot to do with topography. This influence displays obviously in old urban area of cities. Take Luoyang as an example, therefore there are 7 water logging sites out of the total 32 water logging sites locate in Low-lying topography[3].

\subsection{Some problems in the design of rainwater pipe network}

Fig. 2[1] is a schematic diagram of the rain water system.In the design of rain system, the problems below are the basic causes for storm water logging.

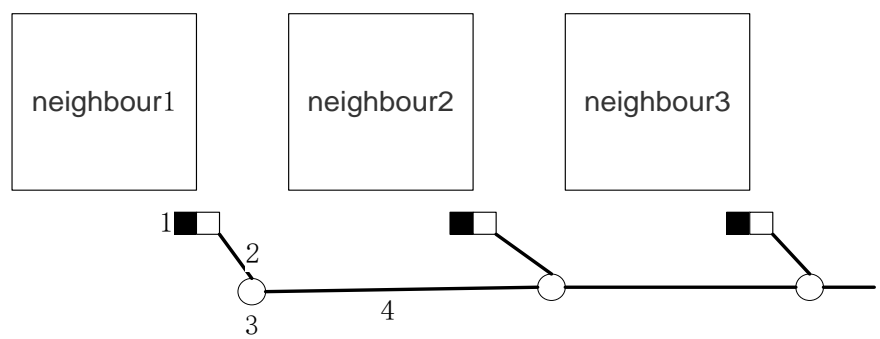

Fig2. Schematic diagram of the storm water systems.

1 inlet; 2 rainwater connecting pipes; 3 storm water manholes; 4 rainwater pipeline

\subsubsection{The design of the rainwater outlet}

In recent years, numerous urban roads in cities have been reconstructed, in particular, some intersections have been repeatedly reconstructed. However such reconstruction is mainly conducted for traffic situation, the construction of inlets for storm water is normally ignored. As figure 2 shows. As the first sites where rainwater enters into rainwater system, the inlets for storm water play a vital role in controlling water logging. If 
incorrect set location or/and number of inlets for storm water are set, water logging will be always resulted in no matter how large the rainwater pipe section is. In particular at some road intersections, the set location and number of inlets are more important.

\subsubsection{There are some problems flow calculation on rainwater pipe network design in the past}

The following problems exist in the old code for design of outdoor wastewater engineering:

(1) The urban planning and rainwater system planning and design of city has insisted the principle of "quick collection and quick elimination" for a long time, which causes less accumulation of rainwater in city, and needs gutter inlet for rainwater collection and storm sewer system and rainwater pumping station for conveying and eliminating rainwater, and problems in any above link will cause storm water logging.

(2) The designed recurrence period is less

(3) The rainfall during is larger

\subsubsection{Catchment area error}

Some designers conducted division and calculation of catchment area only based on topographic map without performing practical exploration on engineering site, which will undoubtedly lead to some errors.

\subsection{Limitation of current rainwater pipe network and the influence of geographical space}

Some ancient city, combined pipe network exists in some sites, and sewage is of certain influence to rainwater discharge; On the other hand, due to increased number of hard roads, increased building density and topographical change at some sites, the rainwater runoff increases accordingly, which entails the requirement of enlarging the dimension of rainwater pipe. However some sites are forbidden to be reconstructed due to some reasons and water logging is likely to occur.

\subsection{Some problems of pipe during maintenance and management of rainwater system}

Many cities have short rains, while during other period, the pipe network is in long unused state. Leakage of pipe is sometime failed to be checked out in time, dust and other depositions caused by improper behavior of city cleaners and street vendors accumulate at inlet areas, the water absorption will be reduced and rainwater connecting pipes will be even blocked. Therefore the water logging will be surely caused when a storm comes.

\subsection{No consideration of reducing rainwater runoff has been taken into} rainwater system-related in other urban construction

During urban construction of some cities, there are following aspects reflecting the ignorance on reducing rainwater runoff:

(1)Near all building roofs are not afforested.

(2) The material used for constructing urban roads, squares, and parking lots are of small permeability coefficient and large runoff coefficient.

(3) During reconstruction of urban roads, the area of green belt decreases. In addition, since the elevation of existing green belt in generally higher than that of roads, it fails to give full play to the infiltration capacity of green bels.

\subsection{Original urban river, canal and lake fail to fully exert flood discharge function}

\section{Countermeasure for solving City waterlogging phenomenon}

According to the cause for cities storm water logging, following methods are recommended to overcome the water logging phenomenon:

\subsection{Rainwater system reconstruction at low-lying areas}

Under the condition where road surface, underground space and economy are favorable, it is suggested to perform radically reconstruction including substituting old pipes with new rainwater pipes of larger diameter, increasing number of rainwater inlets, determining the optimal locations of rainwater inlets, and performing pump reconstruction if pump station is given; However if the conditions are not favorable, it is suggested to increase the number of rainwater inlets, or at least to enhance the maintenance and management of this section of road.

\subsection{Enhance the maintenance and management of rainwater pipe} network

It is suggested to regularly conduct leakage checking, damage repairing, and deposition cleaning for rainwater pipes, especially for branch pipes.
Although the branch pipes have smaller rainwater conveying capacity, they are easily to be blocked and hard to be cleared for its tiny diameter Therefore the branch pipes should be kept in smooth condition, so as to guarantee there will be no water logging at its water absorption area when a storm comes. Before rainy season comes, it is also suggested to radically clean the deposition at all rainwater inlets and connection pipes, so as to avoid blocks of pipes and water logging.

\subsection{Improve Related Urban Facilities of City based on Construction of "Sponge City"}

Sponge City means the city has good flexibility in adapting to environmental change and responding to natural hazard caused by rainwater, internationally what is called "Low Impact Development for Rainwater System Construction" [4]. The natural river, artificial channels, lakes, ponds and other water systems, and green spaces, gardens, permeable roads and squares, green roofs and other urban facilities as a sponge, when rainfall it can absorb water, water storage and water seepage, thus reducing the possibility of urban storm water accumulation. Specific measures include the following aspects:

(1)The designer participating in urban planning and rainwater system planning and design of city uses the concept of "Sponge City" to conduct the urban planning and rainwater system planning and design, the storm water logging phenomenon will be eliminated consequentially from the source.

(2) Through field investigation of current situation of rainwater pipe network and figuring out the links between rainwater pipe and urban rivers, canals and lakes, the storm rain runoff can be reduced.

(3) Greening building roofs, increasing the area of green belts at both sides of road and setting the elevation of green belt lower than that of surrounding road surface, following the principle of reducing urban runoff coefficient when using materials and setting materials mixed ratios for constructing urban roads, squares and parking lots, and setting rainfal regulative pools in conditional residence communities, enterprises and public institutions, and urban public land.

\subsection{Accurately determine all design parameters and increase design standard as much as possible}

\subsection{Reasonable layout of inlet}

At road intersections or areas of topographic relief, the location and number of rainwater inlets should be reasonably set; for streets where the road condition is poor and litters are deposited or vegetable markets, it should set rainwater inlets with catch-basins.

\subsection{Construction of urban forecasting early-warning system}

Construction of urban forecasting early-warning system, designing institutions and municipal administrative departments should actively promote and apply there advanced technologies, so as to achieve verification of urban planning, construction, rainwater pipe network design based on urban storm water logging simulation predicting system; Moreover, municipal administrative departments can search water logging sites through such system and take timely measure to cope with and manage pipe network repairing, preventing before storm comes and eliminating the damage caused by storm water logging hazard.

\section{Conclusion}

In all, the storm water logging hazard of Luoyang city can be reduced by taking following measures:

(1) Enhancing management of rainwater pipe network and reconstructing the rainwater pipe network at low-lying areas.

(2) Accurately determine all design parameters and increase design standard as much as possible. Reasonably allocating location and number of rainfall inlets, setting catch-basin-integrated rainfall inlets at areas where litters are likely to be accumulated.

(3) Enhancing urban greening urban planting, selecting paving material of larger permeability coefficient, setting rainfall regulative pools, fully utilizing the flood storage capacities of urban rivers, canals and lakes to reduce urban storm runoff.

(4) Verification of urban planning, construction, rainwater pipe network design based on urban storm water logging simulation predicting system, and management of rainwater pipe network and related municipal engineering

\section{References}


[1] W. Xinwen. "Problems and Solutions in the Design of Rainwater Pipe Networks". Advanced Materials Research.vols.955-959, pp. 3437-3441, Apr 2014

[2] L.Peihuang,X.Wenlong. Quanzhou lightning storm hit the city, serious water, some schools closed.Quanzhou network.Retrieved from http://www.qzwb.com/gb/content/2016-

$\underline{05 / 10 / \text { content 5319728.htm }}$

[3] W. Xinwen. "The Cause for Storm Water logging in Luoyang and Countermeasure". Journal of Residuals Science and Technology,13(6),44.1-44.5.
[4] Baoxing Qiu, Connotation, Approach and Prospect of Sponge City (LID). Construction Science and Technology. pp.140-143 Jan 2015

\section{Acknowledgements}

1. Department of Science and technology of Henan Province (122102310313)

2. Department of Science and technology of Henan Province (162102310113)

3. Education Department of Henan Province (18A560017) 